\title{
Feasibility study of DCs/CIKs combined with thoracic radiotherapy for patients with locally advanced or metastatic non-small-cell lung cancer
}

Luping Zhang ${ }^{1}$, Yanmei $\mathrm{Xu}^{2}$, Jie Shen ${ }^{1}$, Feng He${ }^{1}$, Dan Zhang ${ }^{1}$, Zhengtang Chen ${ }^{1}$, Yuzhong Duan ${ }^{1 *}$ and Jianguo Sun ${ }^{1 *}$

\begin{abstract}
Background: The combination of dendritic cells (DCs) and cytokine-induced killer cells (CIKs) can induce the anti-tumor immune response and radiotherapy may promote the activity. We aimed to explore the feasibility of DCs/CIKs combined with thoracic radiotherapy (TRT) for patients with locally advanced or metastatic non-small-cell lung cancer (NSCLC).

Method: In this study, patients with unresectable stage III/IV NSCLC and an Eastern Cooperative Oncology Group performance status (ECOG PS) of 0-2 and previously receiving two or more cycles of platinum-based doublet chemotherapy without disease progression received TRT plus DCS/CIKs or TRT alone until disease progression or unacceptable toxicity. The primary endpoint was median progression-free survival (mPFS). In treatment group, patients received four-cycle autologous DCs/CIKs infusion starting from the $6^{\text {th }}$ fraction of irradiation.

Results: From Jan 13, 2012 to June 30, 2014, 82 patients were enrolled, with 21 patients in treatment group and 61 in control group. The mPFS in treatment group was longer than that in control group (330 days vs 233 days, hazard ratio $0.51,95 \% \mathrm{Cl} 0.27-1.0, P<0.05$ ), and the objective response rate (ORR) of treatment group (47.6\%) was significantly higher that of control group $(24.6 \%, P<0.05)$. There was no significant difference in disease control rate (DCR) and median overall survival (mOS) between two groups $(P>0.05)$. The side effects in treatment group were mild and there was no treatment-related deaths.
\end{abstract}

Conclusion: The combination of DCs/CIKs with TRT could be a feasible regimen in treating locally advanced or metastatic NSCLC patients. Further investigation of the regimen is warranted.

Keywords: Dendritic cells, cytokine-induced killer cells, thoracic radiotherapy, non-small cell lung cancer, cytotherapy

\section{Introduction}

Lung cancer is the most commonly diagnosed cancer worldwide ( 1.8 million, $13.0 \%$ of the total), and also a leading cause of cancer death (1.6 million, $19.4 \%$ of the total) [1]. Patients with non-small cell lung cancer (NSCLC) account for more than $80 \%$ of those with lung cancers [2]. Although much progress has been made in the last decade in lung cancer treatment, the overall 5-

\footnotetext{
* Correspondence: cqxayy@foxmail.com; sunjg09@aliyun.com

${ }^{1}$ Cancer Institute of PLA, Xinqiao Hospital, Third Military Medical University,

Chongqing, 400037, China

Full list of author information is available at the end of the article
}

year survival rate is still less than $20 \%$ [3]. More efforts are needed to improve the prognosis of NSCLC patients.

Thoracic radiotherapy (TRT) plays an irreplaceable role in treating NSCLC patients, especially those with medically inoperable or locally advanced unresectable disease [4]. Accumulating evidences show that TRT may stimulate the anti-tumor immune response [5-8]. Tumor cells killed by irradiation of more than a total dose of 10Gy [9] release tumor antigens that induce numerous immune modulatory molecules $[10,11]$ and promote tumor-specific effector $\mathrm{CD}^{+} \mathrm{T}$ cells via dendritic cell (DC) activation [7]. DCs are the major antigen-presenting 
cells, and play a central role in regulating and activating anti-tumor immune response $[12,13]$. CIKs which express both $\mathrm{T}$ cell marker $\mathrm{CD}^{+}$and NK cell marker $\mathrm{CD}^{+} 6^{+}$display a strong anti-tumor activity [14]. DCs/CIKs cytotherapy is clinically efficient and can be well tolerated in tumor patients $[15,16]$. Based on the hypothesis that DCs/CIKs combined with TRT could benefit the NSCLC patients, we therefore sponsored a phase II clinical trial from January 2012 to June 2014, and explored the efficacy, safety and immunologic effects of DCs/CIKs combined with TRT in patients with NSCLC.

\section{Patients and methods}

\section{Study design and patients}

This prospective single-center, open-label, phase II study was conducted at the Cancer Institute of PLA, Xinqiao Hospital, Third Military Medical University, Chongqing, China. This trial was registered at Chinese Clinical Trial Registry (ChiCTR-TRC-12002369, http://www.chictr.org.cn) and approved by the Ethics Committee of General Logistics Department of PLA, China.

Eligible patients were histologically or cytologically (not including sputum cytology) diagnosed with unresectable stage III or IV advanced NSCLC (according to the $7^{\text {th }}$ edition of the General Rule for Clinical and Pathological Record of Lung Cancer) [17]. All enrolled stage III patients were reluctant to receive or were not suitable for concurrent chemoradiotherapy or radical radiotherapy because of certain conditions, such as huge primary tumors, potential risk of heart failure, respiratory dysfunction and previous chemotherapy in other medical center, etc. Other inclusion criteria included an age of 18 years or older at the time of signing consent form; a life expectancy of 3 months or longer at the registration; an Eastern Cooperative Oncology Group performance status (ECOG PS) of 0-2; adequate function of the liver, kidney, heart and hematopoietic system; two or more cycles of previous platinum-based doublet chemotherapy without disease progression. No previous DCs/CIKs cytotherapy or TRT was allowed. One or more measurable lesions are necessary for therapeutic evaluation based on Response Evaluation Criteria in Solid Tumors (RECIST 1.1) [18]. All study participants provided "written informed consent". Major exclusion criteria included an acute infection; any autoimmune disease; a history of severe allergic reaction; HIV-positivity; pregnancy or nursing.

A block randomization was designed at the beginning, with estimated median progression-free survival (mPFS) of 6 months in control group, one-sided significance level of 0.1 and a power of 0.7 . The target sample size was set at 120 patients (1:1), and dropouts were allowed. However, it would take a very long period of time to finish the enrollment because of the high medical cost of DCs/CIKs cytotherapy, which was excluded from medical insurance in China. Therefore, from Jan 13, 2012 to June 30, 2014, enrolled patients were assigned to control group and treatment group at their will instead of randomization. Patients in control group received TRT alone, while the patients in treatment group received TRT in combination with DCs/CIKs cytotherapy that started from the $6^{\text {th }}$ fraction of irradiation (Fig. 1a). The primary endpoint for this clinical trial was mPFS, and the secondary endpoints were objective response rate (ORR), disease control rate (DCR), median overall survival (mOS), PS change and side effects. Immunologic effects were to be explored. After TRT, enrolled patients would continue chemotherapy to reach a standard of 6 cycles in total.

\section{Preparation of autologous DCs and CIKs}

Autologous DCs and CIKs were prepared following the previous studies [19-21] (Fig. 1b). Briefly, peripheral blood mononuclear cells (PBMCs) were isolated by Ficoll-Hypaque gradient density centrifugation, and then cultured in X-VIVO medium for $2 \mathrm{~h}$. The adherent cells were collected for preparing DCs in X-VIVO medium containing granulocyte macrophage colony-stimulating factor (GM-CSF) and interleukin-4 (IL-4). Five days later, tumor necrosis factor- $\alpha$ (TNF- $\alpha$ ) and MUC-1 peptide (SAPDTRPAPGSTAPPAHGVT) (GL Biochem, Shanghai, China) were added into DCs culture for another 2 days. For preparing CIKs, non-adherent cells were cultured in $\mathrm{X}$-VIVO medium containing interferon $\gamma($ IFN $-\gamma)$, CD3 monoclonal antibody, and interleukin-2 (IL-2) for 10 days. The immune phenotype markers CD80, CD83, CD86, and HLA-DR for DCs and CD3, CD56 for CIKs were analyzed by flow cytometry. Contamination of bacteria, fungi and endotoxin in all the cultured samples were detected during the course of cell culture.

\section{DCs/CIKs cytotherapy}

At the beginning of the study (day 0), we collected PBMCs from the patients for culturing DCs and CIKs respectively in vitro. Subsequently, over $1 \times 10^{7} \mathrm{DCs}$ were injected subcutaneously in the lymph node-rich regions (bilateral axillary or inguinal region) on days $7,14,21$, and 28 . Over $1 \times 10^{9}$ CIKs in $100 \mathrm{~mL}$ of of normal saline (NS) $(0.9 \%)$ were infused intravenously once a day for 4 consecutive days from day 11 to day 14 (Fig. 1a).

\section{TRT regimens}

The interval between chemotherapy and enrollment was no less than 14 days. TRT including three-dimensional conformal radiotherapy (3D-CRT) or intensity-modulated radiotherapy (IMRT) was adopted according to NCCN guideline for patients with advanced NSCLC. Contour delineation and radiotherapy plan was designed and confirmed by the professional radiation oncologist. TRT 

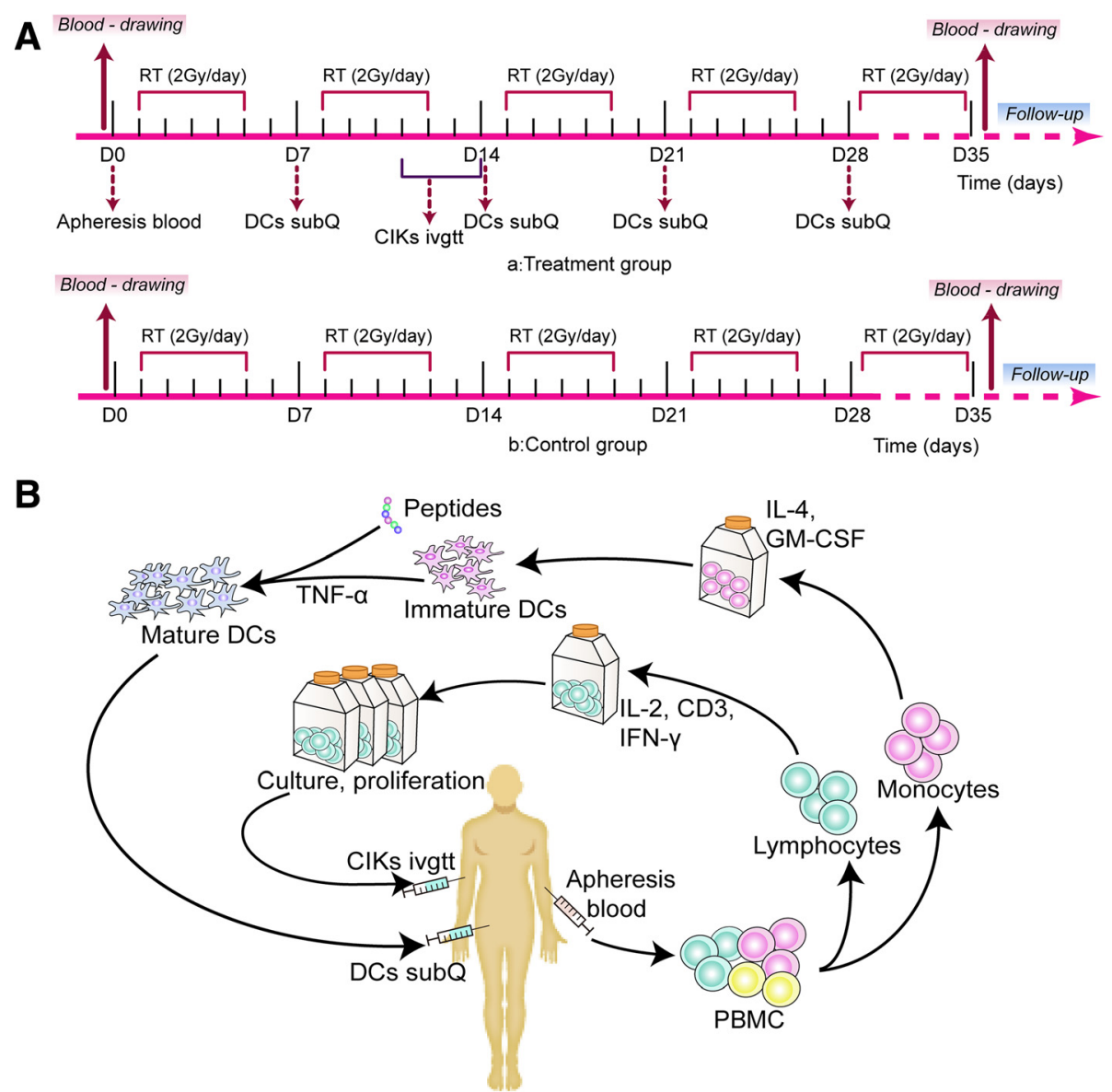

Fig. 1 Study design and workflow. a The study design of treatment group and control group in clinical trial. b The schematic diagram of collection and infusion of autologous DCs/CIKs cells

was delivered at 2 Gy per fraction, 5 fractions per week, to a total dose of 60-66 Gy at planning gross tumor volume (pGTV) in 6-7 weeks. All plans were performed with the support of four-dimensional chest CT. The normal lungs received a limited radiation according to NCCN guidelines.

\section{Assessment of clinical outcomes}

According to RECIST 1.1 [18], the treatment efficacy was classified as complete response (CR), partial response $(\mathrm{PR})$, stable disease (SD), and progression disease (PD). The ORR was defined as the percentage of patients with CR or PR, and DCR was defined as the percentage of patients with $\mathrm{CR}$, or PR, or SD. mPFS was defined as the median time scale from enrollment to disease progression, while mOS was the median time scale from first treatment to death. The follow-up was performed at the $1^{\text {st }}$ and $3^{\text {rd }}$ month after TRT, and then every 3 months for the first year, and every 6 months thereafter. Routine follow-up assessments included physical examinations, vital signs, computed tomographic scans (CT), and laboratory tests.

\section{Assessment of immunologic effects}

Blood-drawing from participants was performed on day 0 and within a week after TRT (Fig. 1a). Cytokines (IL-2, IFN- $\gamma$ ) in serum were detected by enzyme-linked immunosorbent assay (ELISA) (R\&D Systems, MN, USA) following the manufacturer's instruction. For assay of T cell populations and NK cells, $100 \mu \mathrm{L}$ of EDTA anticoagulant blood samples were stained with corresponding antibodies (BD Bioscience), namely, anti-CD3 ${ }^{+}, \mathrm{CD}^{+}$and $\mathrm{CD} 8^{+}$for $\mathrm{T}$ cells, anti-CD3 ${ }^{+}$and $\mathrm{CD} 6^{+}$for NK cells, in darkness for $20 \mathrm{~min}$. Then, erythrocyte lysis buffer was added. After being vortexed for $15 \mathrm{~s}$ and incubated at room temperature for $5 \mathrm{~min}$, the samples were centrifuged to remove the supernatant and washed with PBS. After being resuspended with staining buffer, the samples were analyzed on the BD Aria flow cytometer (BD Bioscience).

\section{PS and side effects}

Adverse effects, such as insomnia, anorexia, fever, skin rash, and joint pain, were monitored and were observed once a week during the therapy and once a month during 
the follow-up. PS was evaluated on day 0 of the study and within a week after the TRT.

\section{Statistical analysis}

The measurement data were expressed as mean \pm standard deviation $(\overline{\mathrm{x}} \pm \mathrm{s})$ and analyzed with the independent Student $t$ test. The enumeration data were analyzed using $X^{2}$ test. Kaplan-Meier curves with the log-rank test were used to estimate mPFS and mOS. Hazard ratio (HR) and $95 \% \mathrm{CI}$ were also calculated by Cox proportional hazard regression models. $P<0.05$ was considered statistical significance.

\section{Results}

\section{Patient characteristics}

From January 13, 2012 to June 30, 2014, a total of 82 patients with locally advanced or metastatic NSCLC were enrolled, with 21 patients in treatment group and 61 in control group (Fig. 2). Clinicopathological characteristics such as age, gender, PS, clinical stage of tumor, previous systemic chemotherapy, pathological type and PS in treatment and control groups were analyzed. None of them showed significant differences (Table 1, $P>0.05$ ), which meant a nearly identical baseline between the two groups.

\section{Clinical outcomes}

The median follow-up time in treatment and control groups was 339 and 393 days, respectively. 0 CR, 10 PR, 9 SD and 2 PD were found in treatment group, and 0 CR, 15 PR, 39 SD and 7 PD were found in control group. ORR in treatment group is higher than that in control group ( $47.6 \%$ vs. $24.6 \%, P=0.04$ ) (Fig. 3). However, no obvious difference in DCR was observed between the two groups $(90.5 \%$ vs. $88.5 \%, P=0.767)$.

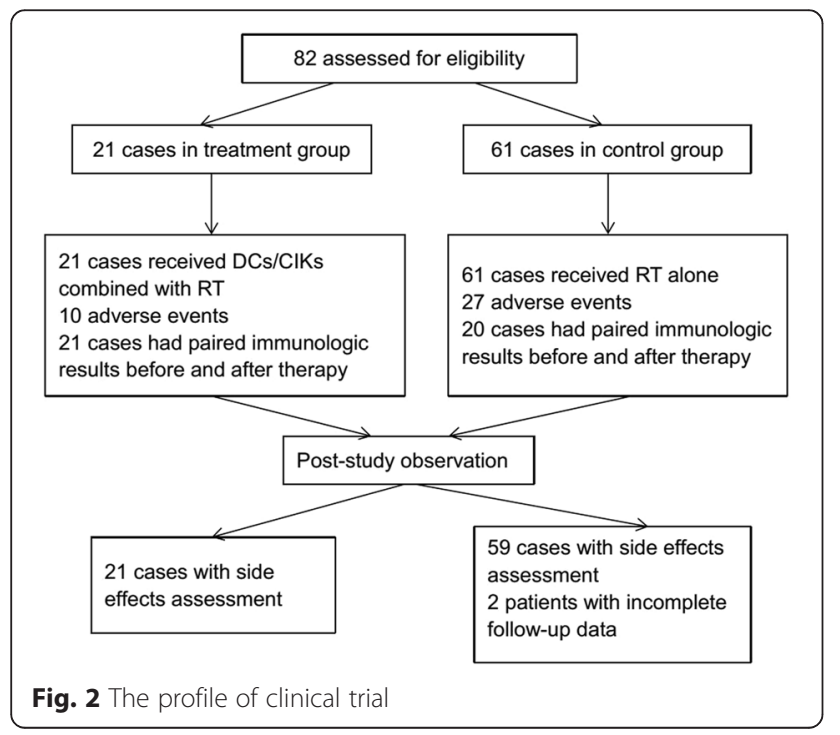

Table 1 Baseline characteristics of two groups

\begin{tabular}{llll}
\hline Characteristics & $\begin{array}{l}\text { Treatment } \\
\text { group }\end{array}$ & $\begin{array}{l}\text { Control } \\
\text { group }\end{array}$ & $P$ value \\
\hline Number & 21 & 61 & \\
Age (years) & $56.6(32-74)$ & $56.4(31-74)$ & 0.95 \\
$\quad$ Mean (Range) & & & \\
Gender & $19(90.5 \%)$ & $53(86.9 \%)$ & \\
$\quad$ Male & $2(9.5 \%)$ & $8(13.1 \%)$ & 0.73 \\
$\quad$ Female & & & \\
Clinical stage & $10(47.6 \%)$ & $37(60.7 \%)$ & \\
$\quad$ III & $11(52.4 \%)$ & $24(39.3 \%)$ & 0.30 \\
$\quad$ V & & & \\
Tumor histology & $8(38.1 \%)$ & $26(42.6 \%)$ & \\
$\quad$ Adenocarcinoma & $13(61.9 \%)$ & $35(57.4 \%)$ & 0.72 \\
$\quad$ Squamous carcinoma & $2.9 \pm 0.7$ & $3.1 \pm 0.8$ & 0.53 \\
Cycles of previous chemotherapy & $0.4 \pm 0.6$ & $0.6 \pm 0.7$ & 0.35 \\
\hline PS score & & &
\end{tabular}

As for long-term evaluation, the mPFS of treatment group (330 days) was significantly longer than that of control group (233 days) (HR 0.51, $95 \%$ CI 0.27-1.0, $P=0.0483)$. However, there was no significant difference in mOS between treatment group (400 days) and control group (460 days) (HR 0.83, $95 \%$ CI 0.41-1.69, $P=0.606$ ) (Fig. 4).

\section{Immunologic response}

Among the 61 patients in control group, complete immunologic results were obtained in only 20 cases before and after TRT. There was a lack of some medical materials in the rest patients because of their refusal to draw blood and the delayed follow-up, and some other reasons. These 20 cases were analyzed by assessing the baseline (Table 2) and immunologic effects. The results of cytokines (IL-2,

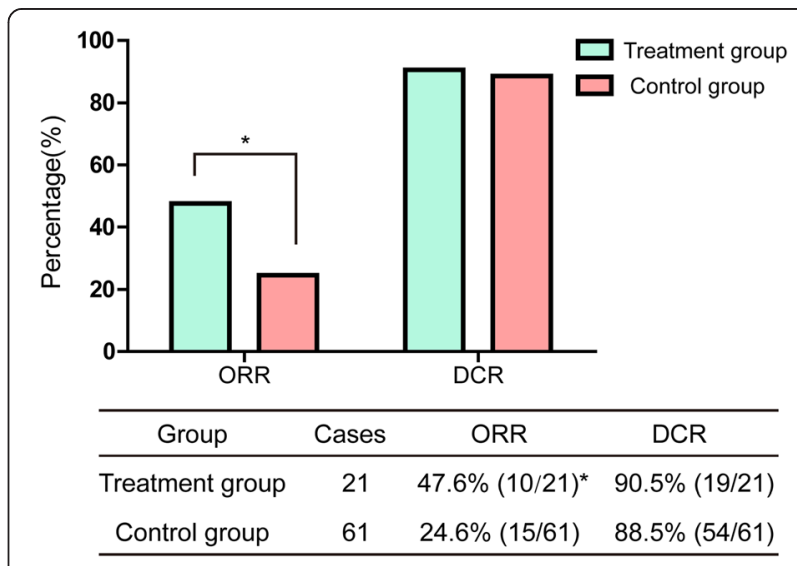

Fig. 3 The short-term clinical effects. ${ }^{*} \mathrm{ORR}$ is significantly higher in treatment group $(P<0.05)$ 

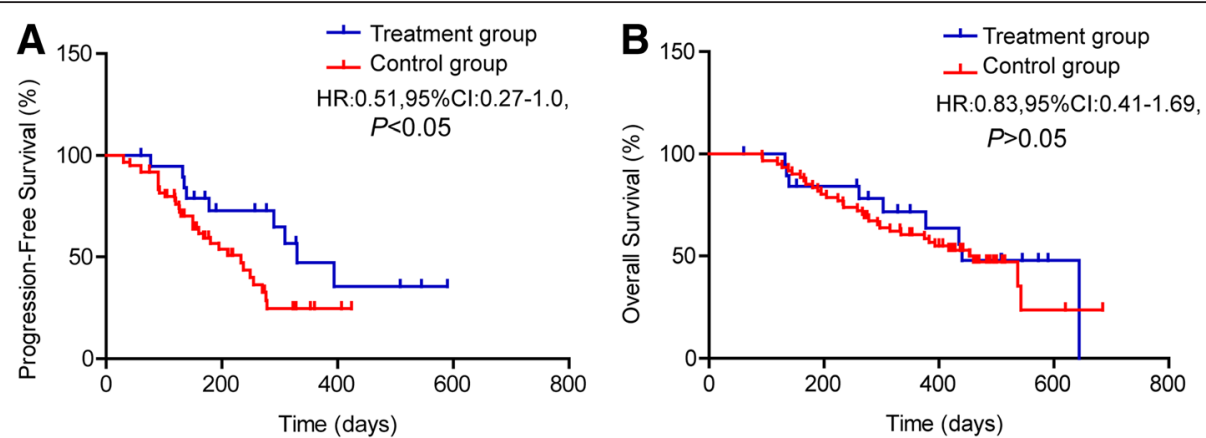

Fig. 4 Kaplan-Meier curves of mPFS and mOS. a. Compared with control group, mPFS in treatment group is significantly longer $(P<0.05)$. b. No significant mOS difference between treatment group and control group $(P>0.05)$

IFN- $\gamma$ ), T cell populations and NK cells were analyzed. The serum levels of IL-2 and IFN- $\gamma$ did not differ significantly between the two groups both before and after the TRT (Table 3, $P>0.05$ ). Moreover, there were no obvious changes in the percentage of $\mathrm{CD}^{+}, \mathrm{CD}^{+} \mathrm{CD}^{+}$, $\mathrm{CD}^{+} \mathrm{CD}^{+}, \mathrm{CD}^{+} / \mathrm{CD}^{+}{ }^{+} \mathrm{T}$ cell ratio and $\mathrm{CD}^{-}{ }^{-} \mathrm{CD} 56^{+} \mathrm{NK}$ cells before and after TRT in treatment group $(P>0.05)$. However, it should be noted that there was a decrease in $\mathrm{CD}^{+} / \mathrm{CD}^{+} \mathrm{T}$ cell ratio after TRT in control group, with a $P$ value close to 0.05 (Table $3, P=0.08$ ).

\section{PS and side effects}

At the beginning of the study, the PS in treatment and control groups was $0.4 \pm 0.6$ and $0.6 \pm 0.7$, respectively (Table 1). At the end of TRT, the PS in treatment and control groups were $0.9 \pm 0.8$ and $1.4 \pm 0.6$, respectively. Little PS increase was found in treatment group after TRT $(0.48 \pm 0.7)$. However, obvious PS increase was recorded in control group $(0.9 \pm 0.7)$. The PS increase in

Table 2 Baseline characteristics of two groups in immunologic response

\begin{tabular}{llll}
\hline Characteristics & $\begin{array}{l}\text { Treatment } \\
\text { group }\end{array}$ & $\begin{array}{l}\text { Control } \\
\text { group }\end{array}$ & $P$ value \\
\hline Number & 21 & 20 & \\
$\begin{array}{l}\text { Age (years) } \\
\quad \text { Mean (Range) }\end{array}$ & $56.6(32-74)$ & $54.3(39-68)$ & 0.48 \\
Gender & $19(90.5 \%)$ & $17(85 \%)$ & \\
$\quad$ Male & $2(9.5 \%)$ & $3(15 \%)$ & 0.66 \\
$\quad$ Female & $10(47.6 \%)$ & $10(50 \%)$ & \\
Clinical stage & $11(52.4 \%)$ & $10(50 \%)$ & 0.88 \\
$\quad$ III & & & \\
$\quad$ IV & $8(38.1 \%)$ & $10(50 \%)$ & \\
Tumor histology & $13(61.9 \%)$ & $10(50 \%)$ & 0.44 \\
$\quad$ Adenocarcinoma & $2.9 \pm 0.7$ & $2.4 \pm 0.5$ & 0.06 \\
$\quad$ Squamous carcinoma & $0.4 \pm 0.6$ & $0.5 \pm 0.6$ & 0.91 \\
\hline Cycles of previous chemotherapy & &
\end{tabular}

treatment group was significantly lower than that in control group $(P=0.018$, Table 4$)$.

Side effects were assessed in all the 21 cases in treatment group, and 59 of 61 cases in control group, with incomplete follow-up information in 2 cases. The functions of the liver, kidney and heart of all the participants remained normal at the end of the TRT treatment. The most commen side effects were fever, anorexia, nausea, vomiting, myelosuppression, and radiation pneumonitis (Table 3). Most of them were at level I II, except radiation pneumonitis. Radiation pneumonitis with grade 3 was observed in 3 patients in treatment group (14.3\%), and 9 patients in control group (15.3\%). All patients recovered after suitable treatment within 2 months. There were no cases with grade 4 radiation pneumonitis and treatment-related deaths.

\section{Discussion}

Cancer cytotherapy is a novel therapeutic approach with great potential [22-24]. Since the report of the first DCs-based cancer vaccine clinical trial in 1995 [25], a lot of trials have been designed and conducted [26, 27]. In 2010, Food and Drug Administration (FDA) approved the first DCs-based vaccine Provenge for the treatment of advanced prostate cancer [23, 28]. Additionally, the cytotoxic and regulatory anti-tumor effects of CIKs are also attractive and promising. The combination of DCs with CIKs is a viable adoptive cytotherapy with a strong anti-tumor effect $[29,30]$. It was shown that irradiation enhanced MHC I expression, and changed the tumor microenvironment to boost greater infiltration of immuneeffector cells [31-33]. Tumor cells killed by irradiation released tumor antigens which were presented by ectopic DCs [10]. Both preclinical and clinical researches proved that radiotherapy combined with cytotherapy elicited greater anti-tumor response [34, 35].

As for the clinical outcomes of our study, a longer mPFS was observed in treatment group than in control group (330 days vs 233 days, $P<0.05$ ), and ORR was higher in treatment group $(47.6 \%$ vs $24.6 \%, P<0.05)$. 
Table 3 Immunology response of patients $(\bar{x} \pm s)$

\begin{tabular}{|c|c|c|c|c|c|c|c|}
\hline Group & $\mathrm{CD}^{+}(\%)$ & $\mathrm{CD}^{+} \mathrm{CD}^{+}(\%)$ & $\mathrm{CD}^{+} \mathrm{CD}^{+}(\%)$ & $\mathrm{CD}^{+} / \mathrm{CD}^{+}{ }^{+}$ & $\mathrm{CD}^{-}{ }^{-} \mathrm{CD}^{2} 6^{+}(\%)$ & IL-2 (ng/L) & IFN-r (pg/mL) \\
\hline \multicolumn{8}{|l|}{ Treatment group } \\
\hline Pre-treatment & $62.16 \pm 13.62$ & $33.64 \pm 10.05$ & $25.86 \pm 10.30$ & $1.55 \pm 0.88$ & $17.83 \pm 9.04$ & $330.42 \pm 79.25$ & $575.85 \pm 179.85$ \\
\hline Post-treatment & $66.34 \pm 13.65$ & $34.63 \pm 13.28$ & $29.73 \pm 11.14$ & $1.45 \pm 0.97$ & $17.31 \pm 9.50$ & $330.94 \pm 66.12$ & $567.12 \pm 151.64$ \\
\hline$P$ value & 0.3 & 0.716 & 0.119 & 0.684 & 0.806 & 0.979 & 0.831 \\
\hline \multicolumn{8}{|l|}{ Control group } \\
\hline Pre-treatment & $68.70 \pm 15.48$ & $39.48 \pm 12.76$ & $27.30 \pm 8.79$ & $1.57 \pm 0.67$ & $10.25 \pm 6.12$ & $358.37 \pm 49.00$ & $491.19 \pm 60.00$ \\
\hline Post-treatment & $70.43 \pm 19.67$ & $33.6471 \pm 18.02$ & $33.65 \pm 17.19$ & $1.27 \pm 0.96$ & $8.52 \pm 6.52$ & $376.09 \pm 44.44$ & $507.32 \pm 59.87$ \\
\hline$P$ value & 0.705 & 0.051 & 0.077 & 0.08 & 0.378 & 0.186 & 0.481 \\
\hline
\end{tabular}

Although there was no significant difference in DCR and mOS between the two groups $(P>0.05)$, the positive results in mPFS and ORR were still encouraging. Thus, patients treated with DCs/CIKs combined with TRT had a better clinical benefit. In the present study, we started DCs/CIKs cytotherapy from the $6^{\text {th }}$ fraction of TRT to release enough tumor antigens. Our results validate the hypothesis that tumor antigens released by TRT could enhance tumor-specific killing via ectopic DCs/CIKs infusion.

For safety analysis, during the combination therapy of DCs/CIKs and TRT, a majority of side effects were mild, tolerant and similar to TRT alone. No new safety signals were identified, and no treatment-related deaths occurred. In addition, we found a significant PS increase after TRT in control group $(P<0.05)$. Nevertheless, there was a minor PS increase in treatment group $(P>0.05)$. It suggests that combined cytotherapy improves the PS for advanced patients receiving TRT. Thus, DCs/CIKs in combination with TRT shows a good safety profile.

Cancer patients often suffer from immune deficiency, including a decrease in $\mathrm{CD}^{+} / \mathrm{CD}^{+} \mathrm{T}$ cell ratio, especially during a long period of systemic chemotherapy [36]. In the present study, we found that there was a tendency of a decrease in $\mathrm{CD}^{+} / \mathrm{CD}^{+} \mathrm{T}$ cell ratio after TRT in control group $(P=0.08)$ instead of in treatment group (Table 2$)$. Thus, a reasonable explanation could be that radical TRT with conventional fractionation causes immune suppression in control group, and DCs/CIKs cytotherapy partially rescues immune suppression induced by TRT in treatment group.

Meanwhile, the current study detected other cytokines, such as IL-2 and IFN- $\gamma$ in peripheral blood, which were supposed to play critical roles in specific immunological effects and promoting innate and adaptive immune responses [37]. The serum levels of IL-2 and IFN- $\gamma$ did not change significantly after TRT in both groups $(P>0.05)$. Since the immune response is very complex in DC/CIK combined with TRT, further research is needed to reveal cytokine activity in the future.

Given that irradiation-mediated immune responses alter the tumor micro-environment, more and more researches have explored that local radiation combined with CTLA-4 blockade [38] or PD-L1 blockade [39] could promote anti-tumor immunity. Our results also suggest that the combination of cytotherapy with TRT is a novel feasible application. It shows better clinical benefit, a good tolerance, minor PS change, and promotes the

Table 4 PS and side effects

\begin{tabular}{|c|c|c|c|c|c|c|}
\hline \multirow[t]{2}{*}{ Characteristics } & \multicolumn{3}{|c|}{ Treatment group $(n=21)$} & \multicolumn{3}{|c|}{ Control group $(n=59)$} \\
\hline & Grade 1-2 & Grade 3 & Grade 4 & Grade 1-2 & Grade 3 & Grade 4 \\
\hline Fever & $5(23.8 \%)$ & 0 & 0 & $13(22.0 \%)$ & 0 & 0 \\
\hline Anorexia & $3(14.3 \%)$ & 0 & 0 & $6(10.2 \%)$ & 0 & 0 \\
\hline Allergy & $1(4.8 \%)$ & 0 & 0 & 0 & 0 & 0 \\
\hline Nausea, vomiting & $3(14.3 \%)$ & 0 & 0 & $9(15.3 \%)$ & 0 & 0 \\
\hline Heart function & 0 & 0 & 0 & 0 & 0 & 0 \\
\hline Liver function & 0 & 0 & 0 & 0 & 0 & 0 \\
\hline Renal function & 0 & 0 & 0 & 0 & 0 & 0 \\
\hline Myelosuppression & $2(9.5 \%)$ & 0 & 0 & 8 (13.6 \%) & 0 & 0 \\
\hline Radiation pneumonitis & 4 (19.0 \%) & $3(14.3 \%)$ & 0 & $11(18.6 \%)$ & $9(15.3 \%)$ & 0 \\
\hline PS change after TRT & $0.48 \pm 0.7^{*}$ & & & $0.9 \pm 0.7$ & & \\
\hline
\end{tabular}

*PS change is significantly better than control group $(P<0.05)$ 
immunity to some extent. However, further studies are needed with larger sample sizes. In addition, due to the lack of randomization and thus possible bias (e.g. more wealth, better education, better supportive care in treatment group), activity needs to be further evaluated in a properly designed randomized trial. Standardized treatment schedule and detailed mechanism of DCs/CIKs combined with TRT should be elucidated in the ongoing research.

\section{Conclusions}

Our study confirms the efficiency and safety of the combination of DCs/CIKs cytotherapy with TRT in advanced NSCLC. Indeed, this novel strategy enhances immunity, improves ORR, prolongs mPFS, and barely changes PS, with no severe treatment-related side effects. It is therefore a feasible regimen for patients with advanced NSCLC.

\section{Competing interests}

The authors declare that they have no competing interests.

\section{Authors' contributions}

LZ carried out the group patients, participated assessment of clinical outcomes and drafted the manuscript. JS Preparation of autologous DCs and CIKs. FH detected the Cytokines. DZ operated the BD Aria flow cytometer. YX participated in the follow-up and performed the statistical analysis. ZC performed the thoracic radiotherapy regimens. YD took part in the clinical design and enrollment. JS conceived of the study, and participated in its design and coordination and helped to draft the manuscript. All authors read and approved the final manuscript.

\section{Acknowledgements}

This work was supported by the National Natural Science Foundation of China (No. 81272496), Chongqing Natural Science Foundation (No. cstc2012jjB10003, cstc2012jjA10096), Clinical Research Fund of Third Military Medical University (No. 2011XLC38). We also appreciate the English editing by Department of Medical English, Third military medical university.

\section{Author details}

${ }^{1}$ Cancer Institute of PLA, Xinqiao Hospital, Third Military Medical University, Chongqing, 400037, China. ${ }^{2}$ Oncology Department, Leshan People's Hospital, Sichuan, 614000, China.

Received: 24 December 2015 Accepted: 13 April 2016

Published online: 21 April 2016

\section{References}

1. Ferlay J, Soerjomataram I, Dikshit R, Eser S, Mathers C, Rebelo M, et al. Cancer incidence and mortality worldwide: sources, methods and major patterns in GLOBOCAN 2012. International journal of cancer. Journal international du cancer. 2015;136(5):359-86.

2. Brodowicz T, Krzakowski M, Zwitter M, Tzekova V, Ramlau R, Ghilezan N, et al. Cisplatin and gemcitabine first-line chemotherapy followed by maintenance gemcitabine or best supportive care in advanced non-small cell lung cancer: a phase III trial. Lung Cancer. 2006;52(2):155-63.

3. Allemani C, Weir HK, Carreira H, Harewood R, Spika D, Wang XS, et al. Global surveillance of cancer survival 1995-2009: analysis of individual data for 25676887 patients from 279 population-based registries in 67 countries. Lancet. 2015;385(9972):977-1010.

4. Panakis N, McNair HA, Christian JA, Mendes R, Symonds-Tayler JR, Knowles $C$, et al. Defining the margins in the radical radiotherapy of non-small cell lung cancer (NSCLC) with active breathing control (ABC) and the effect on physical lung parameters. Radioth Oncol. 2008;87(1):65-73.

5. Apetoh L, Ghiringhelli F, Tesniere A, Obeid M, Ortiz C, Criollo A, et al. Toll-like receptor 4-dependent contribution of the immune system to anticancer chemotherapy and radiotherapy. Nat Med. 2007;13(9):1050-9.
6. Liao YP, Wang CC, Schaue D, Iwamoto KS, McBride WH. Local irradiation of murine melanoma affects the development of tumour-specific immunity. Immunology. 2009;128(1 Suppl):e797-804.

7. Gupta A, Probst HC, Vuong V, Landshammer A, Muth S, Yagita H, et al. Radiotherapy promotes tumor-specific effector CD8+ T cells via dendritic cell activation. J Immunol. 2012;189(2):558-66.

8. Gameiro SR, Jammeh ML, Wattenberg MM, Tsang KY, Ferrone S, Hodge JW. Radiation-induced immunogenic modulation of tumor enhances antigen processing and calreticulin exposure, resulting in enhanced T-cell killing. Oncotarget. 2014;5(2):403-16.

9. Chi KH, Liu SJ, Li CP, Kuo HP, Wang YS, Chao Y, et al. Combination of conformal radiotherapy and intratumoral injection of adoptive dendritic cell immunotherapy in refractory hepatoma. J Immunother. 2005:28(2):129-35.

10. Friedman EJ. Immune modulation by ionizing radiation and its implications for cancer immunotherapy. Curr Pharm Design. 2002;8(19):1765-80.

11. Finkelstein SE, Timmerman R, McBride WH, Schaue D, Hoffe SE, Mantz CA, et al. The confluence of stereotactic ablative radiotherapy and tumor immunology. Clin Dev Immunol. 2011;2011:439752.

12. Villadangos JA, Schnorrer P. Intrinsic and cooperative antigen-presenting functions of dendritic-cell subsets in vivo. Nat Rev Immunol. 2007;7(7):543-55.

13. Steinman RM, Banchereau J. Taking dendritic cells into medicine. Nature. 2007;449(7161):419-26

14. Sangiolo D, Mesiano G, Carnevale-Schianca F, Piacibello W, Aglietta M, Cignetti A. Cytokine induced killer cells as adoptive immunotherapy strategy to augment graft versus tumor after hematopoietic cell transplantation. Expert Opin Biol Th. 2009;9(7):831-40.

15. Toomey PG, Vohra NA, Ghansah T, Sarnaik AA, Pilon-Thomas SA. Immunotherapy for gastrointestinal malignancies. Cancer Control. 2013;20(1):32-42.

16. Cui $Y$, Yang $X$, Zhu W, Li J, Wu X, Pang Y. Immune response, clinical outcome and safety of dendritic cell vaccine in combination with cytokine-induced killer cell therapy in cancer patients. Oncol Lett. 2013;6(2):537-41.

17. The Japan Lung Cancer Society. General rule for clinical and pathological record of lung cancer. 7th ed. Tokyo: Kanehara Press; 2010.

18. Eisenhauer EA, Therasse P, Bogaerts J, Schwartz LH, Sargent D, Ford R, et al. New response evaluation criteria in solid tumours: revised RECIST guideline (version 1.1). Eur J Cancer. 2009:45(2):228-47.

19. Nicol AJ, Tazbirkova A, Nieda M. Comparison of clinical and immunological effects of intravenous and intradermal administration of alpha-galactosylceramide (KRN7000)-pulsed dendritic cells. Clin Cancer Res. 2011;17(15):5140-51.

20. Zhang SN, Choi IK, Huang JH, Yoo JY, Choi KJ, Yun CO. Optimizing DC vaccination by combination with oncolytic adenovirus coexpressing IL-12 and GM-CSF. Mol Ther. 2011;19(8):1558-68.

21. Ma Y, Zhang Z, Tang L, Xu YC, Xie ZM, Gu XF, et al. Cytokine-induced killer cells in the treatment of patients with solid carcinomas: a systematic review and pooled analysis. Cytotherapy. 2012;14(4):483-93.

22. Kantoff PW, Higano CS, Shore ND, Berger ER, Small EJ, Penson DF, et al. Sipuleucel-T immunotherapy for castration-resistant prostate cancer. New Engl J Med. 2010;363(5):411-22.

23. Mellman I, Coukos G, Dranoff G. Cancer immunotherapy comes of age. Nature. 2011:480(7378):480-9.

24. Szyszka-Barth K, Ramlau K, Gozdzik-Spychalska J, Spychalski L, Bryl M, GoldaGocka I, et al. Actual status of therapeutic vaccination in non-small cell lung cancer. Contemp Oncol (Pozn). 2014;18(2):77-84.

25. Mukherji B, Chakraborty NG, Yamasaki S, Okino T, Yamase H, Sporn JR, et al. Induction of antigen-specific cytolytic T cells in situ in human melanoma by immunization with synthetic peptide-pulsed autologous antigen presenting cells. Proc Natl Acad Sci U S A. 1995;92(17):8078-82.

26. Draube A, Klein-Gonzalez N, Mattheus S, Brillant C, Hellmich M, Engert A, et al. Dendritic cell based tumor vaccination in prostate and renal cell cancer: a systematic review and meta-analysis. PLoS One. 2011;6(4):e18801.

27. Engell-Noerregaard L, Hansen TH, Andersen MH, Thor SP, Svane IM. Review of clinical studies on dendritic cell-based vaccination of patients with malignant melanoma: assessment of correlation between clinical response and vaccine parameters. Cancer Immunol Immun. 2009;58(1):1-14.

28. Small EJ, Fratesi P, Reese DM, Strang G, Laus R, Peshwa MV, et al. Immunotherapy of hormone-refractory prostate cancer with antigen-loaded dendritic cells. Clin Oncol. 2000;18(23):3894-903.

29. Rosenberg SA, Restifo NP, Yang JC, Morgan RA, Dudley ME. Adoptive cell transfer: a clinical path to effective cancer immunotherapy. Nat Rev Cancer. 2008;8(4):299-308 
30. Wang D, Zhang B, Gao H, Ding G, Wu Q, Zhang J, et al. Clinical research of genetically modified dendritic cells in combination with cytokine-induced killer cell treatment in advanced renal cancer. BMC Cancer. 2014;14(1):251.

31. Lugade AA, Moran JP, Gerber SA, Rose RC, Frelinger JG, Lord EM. Local radiation therapy of B16 melanoma tumors increases the generation of tumor antigen-specific effector cells that traffic to the tumor. J Immunol. 2005;174(12):7516-23.

32. Garnett CT, Palena C, Chakraborty M, Tsang KY, Schlom J, Hodge JW. Sublethal irradiation of human tumor cells modulates phenotype resulting in enhanced killing by cytotoxic T lymphocytes. Cancer Res. 2004;64(21):7985-94.

33. Chakraborty M, Wansley EK, Carrasquillo JA, Yu S, Paik CH, Camphausen K, et al. The use of chelated radionuclide (samarium-153ethylenediaminetetramethylenephosphonate) to modulate phenotype of tumor cells and enhance T cell-mediated killing. Clin Cancer Res. 2008:14(13):4241-9.

34. Kwilas AR, Donahue RN, Bernstein MB, Hodge JW. In the field: exploiting the untapped potential of immunogenic modulation by radiation in combination with immunotherapy for the treatment of cancer. Front Oncol. 2012;2:104.

35. Hodge JW, Sharp HJ, Gameiro SR. Abscopal regression of antigen disparate tumors by antigen cascade after systemic tumor vaccination in combination with local tumor radiation. Cancer Biother Radio. 2012;27(1):12-22.

36. Muhonen T, Hahka-Kemppinen M, Pakkala S, Pyrhonen S. Decreasing CD4/CD8 ratio during prolonged four-drug chemotherapy plus interferon treatment for metastatic melanoma. J Immunol. 1994;15(1):67-73.

37. Yang L, Ng KY, Lillehei KO. Cell-mediated immunotherapy: a new approach to the treatment of malignant glioma. Cancer Control. 2003;10(2):138-47.

38. Demaria S, Kawashima N, Yang AM, Devitt ML, Babb JS, Allison JP, et al. Immune-mediated inhibition of metastases after treatment with local radiation and CTLA-4 blockade in a mouse model of breast cancer. Clin Cancer Res. 2005;11(2 Pt 1):728-34.

39. Deng L, Liang H, Burnette B, Beckett M, Darga T, Weichselbaum RR, et al. Irradiation and anti-PD-L1 treatment synergistically promote antitumor immunity in mice. J Clin Invest. 2014;124(2):687-95.

\section{Submit your next manuscript to BioMed Central and we will help you at every step:}

- We accept pre-submission inquiries

- Our selector tool helps you to find the most relevant journal

- We provide round the clock customer support

- Convenient online submission

- Thorough peer review

- Inclusion in PubMed and all major indexing services

- Maximum visibility for your research

Submit your manuscript at www.biomedcentral.com/submit

C Biomed Central 